\title{
Using Literature Circle Technique To Organize Group- Work Activities In English Speaking Lessons For Students At Grade 10, Thai Nguyen High School
}

\author{
Pham Thi Kieu Oanh**, Dinh Thi Lien** \\ Foreign languages education faculty, Thai Nguyen University of Education \\ DOI: 10.29322/IJSRP.11.08.2021.p11651 \\ http://dx.doi.org/10.29322/IJSRP.11.08.2021.p11651
}

\begin{abstract}
Nowadays, the significance of cooperative learning inside the classroom to students who study language is undeniable. This study is conducted to examine the effect of literature circle technique in cooperative activities inside the classroom of English-speaking lessons for students at Class 10A4, Thai Nguyen High School, Thai Nguyen City, Vietnam. Particularly, the researchers aim to explore a) the current state of cooperative learning at grade 10, Thai Nguyen High School, b) the struggles that English teachers at Thai Nguyen High School experienced when holding cooperative activities inside the classroom, d) attitudes of the students and teachers when organizing and working with literature circle technique in speaking lessons. The participants of this study were 47 students from class 10A4, 10 English teachers and 1 practical teacher at Thai Nguyen High School. Questionnaires, interviews and observation checklists were used to collect data. The findings proved that although students were offered various chances to take part in cooperative learning activities, these kinds of task were not really effective to motivate and improve their learning. There were two main reasons for this. First, the learners did not have truly and necessarily internal motivations (positive interdependence among group members) to take part in cooperative tasks. Second, the individuals' contributions to cooperative tasks were not assessed in appropriate ways to help them be more engaged in accomplishing the tasks. Additionally, the study also explored that the English teachers at Thai Nguyen High School encountered a variety of difficulties in organizing cooperative learning activities inside the classroom. Based on these facts, this study provided recommendations to high school English teachers by implementing literature circle technique to organize cooperative learning in speaking lessons.
\end{abstract}

Index Terms- Literature Circles, Techniques, Cooperative Learning, High School English Teaching, Oral Skills

\section{INTRODUCTION}

$\mathrm{C}_{1}$ ooperative learning in the speaking classes is considered as a crucial task for students due to its considerable benefits to their language acquisition. Cooperative learning develops interactive and communicative skills which are the essential skills in nowadays' society. Petty (2001) suggests that understanding among students inside the classroom can be built through cooperative work. Therefore, cooperative tasks are extremely important for speaking lessons because the speaking skills can only be improved when the learners have opportunities to interact and communicate with each other. However, there is the fact that the interaction among students to students in the classroom cannot be easily attained. Both students and teachers had some certain difficulties when cooperative learning process was taken place. First of all, there were some group mates who often took the domination of the whole group. Secondly, when doing the cooperative tasks, the responsibilities among group members were often not equal to each other. Furthermore, the unclear assigned duties to the pupils in one group was also one of the difficulties that the pupils encountered. Also, the teachers faced with many problems when holding collaborative tasks in the classroom. They got the difficulties in giving marks and evaluating the group members. Moreover, as cooperative learning activities started, some teachers found out that they sometimes loose the control of the whole class. Be aware of the importance of cooperative learning and the students' and teachers' struggles upon using this model, the researchers consider a new technique - literature circle technique which is believed to be a suitable approach to deal with the above-mentioned problems. The done research about literature circle technique has proved that this model has got several considerable elements to organize students' group discussions. Bedee (2010) concludes that learners, even those who are not really involved in group discussions, are encouraged to talk by working in group towards using the literature circles. As in the same vein, Jacobs (2015) finds out that when taking in this model, the students seem to be more interested in communicating with their group mates because they often question each other and ask for the explanation. Although there have been numerous previous research studied about the application of literature circles on teaching and learning, most of them are about using literature circles to improve reading skills. There have not yet been any researchers doing a research on using literature circle technique on organizing cooperative learning activities in English speaking lessons. All the aforementioned factors have created motivation for the researchers to conduct a research paper entitled "Using Literature Circle technique to organize group-work activities in English speaking lessons for students at grade 10, Thai Nguyen High School" 


\section{II. LITERATURE REVIEW}

\section{The definition of cooperative learning}

Due to its considerable advantages, cooperative learning has been studied in many works in the past century, and this term has been defined in different ways. Williams (2002) describes that cooperative learning is a teaching technique, which help students to improve their study results by collaborating and interacting with their peers in small groups. Along the same lines, Kagan \& Olsen (1992, as cited in Lin, 2009) suggest that cooperative learning provides opportunities for students not only to accomplish the task together but also improve their own and their peers' learning results. In other words, cooperative learning can be understood as carefully planned and structured teaching strategies which hold students in small groups to do a task together. It is worth to notice that the students in the same group do not compete with each other but to help and foster other group members to complete their parts in order to achieve the final goals of the group as a whole. Therefore, this method helps to increase motivation for students to study.

\section{Benefits of cooperative learning to speaking skills}

Basing on the results of other studies, Lin (2009) concludes that cooperative learning is an ideal strategy to help students improve their language, especially their speaking skills. There are several demonstrated benefits of this technique. Wang (2017) concludes that in all done studies, after the students joined in cooperative class, their speaking-skill results of post-tests were all higher than pre-test. That is to say, cooperative learning seems to be an effective way to improve the learners' oral skills.

Here are some common benefits of cooperative learning to the students:

- Develop group work skills

- Increase students' talking time

- Forster and develop interpersonal relationships and build positive friendships

- Help students use language creatively and confidently

- Enhance students' satisfaction with the learning experience

- Create an environment of active, involved, exploratory learning

\section{The definition of Literature Circle technique}

The concepts of literature circles were defined by many famous researchers in the world. Among them, however, the most popular definition is Daniels's (2006). He defines that literature circles are small peer-led discussions about a common chosen stories among students in a group. In every group, each group member will take responsibility that is different from the others. After a previous of reading, the participants gather to discuss about the books. In order to maintain the discussions, each student in a group has to perform his/her role in this reading circle, and the others are supposed to give them some feedback, and questions. The group members set up common schedules to meet each other and discuss about the books with the roles rotating in each section. When finishing reading the stories, the groups can share their discussions to the whole class. Then, the circles are completed. The new circles continue to be formed basing on the books or stories that students choose.

Daniels (2002, as cited in Bedee, 2010) suggests 11 essential features for literature circles. However, in this study, the researchers decided not to adapt all these 11 essential features but alter some of them as the components below:

Similar elements as in Daniels's model (2002, as cited in Bedee, 2010):

- $\quad$ The group discussions are still peer-led

- $\quad$ The group working environment is also open, friendly, and favorable

- $\quad$ The teacher's role during the group discussions is an observer and facilitator

- Marks are given based on both teacher's observation and students' self-evaluation.

- The spirit of learning inside the classroom should be interesting and fun

- When one topic is finished, the groups have to report to the class what they have discussed, then the new circles continue to be run, and the roles in the groups are rotated among the group members.

Implemented features:

- Instead of students' choice of book as Daniels's model, teacher is the one to choose the topic for the students to discuss about

- The groups are formed by the students' seating positions in the class (4 students will be a group). Teacher can make any changes in the participants of the groups appropriately.

- $\quad$ All the groups have the same topic

- $\quad$ Students will work in literature circles inside the classroom (it means that there will be no regular schedules for students to meet apart from the lessons)

\section{The adaptability of literature circle techniques}

Literature circle method has been adapted in many different learning circumstances. After reviewing the literature relating to the term of literature circle, one can summarize that this method is not always implemented in the same ways among all classes. The teachers tend to adapt and modify this technique in order to fit with their students' levels and needs. Here are some examples of the adaptability of literature circles into classrooms of different countries, with different students' levels and needs:

Dillon (2007, as cited in Coccia, 2015) suggests that she decides to make a significant modification to the original literature circle technique of Daniels to make it suitable for her college students. The researcher changes some students' roles within the method to 
foster the discussions. In the same vein, Thomas (2014, as cited in Coccia, 2015) also makes a change into the basic literature circles of Daniels (2006) to fit with her students' needs. She finds out that students are tired and get bored with face-to-face classes and discussions, so Thomas (2014) runs online literature circles to help students having new learning environment and experience. It can be said that the adaptability of literature circles is mainly based on students' age levels and students' needs. However, some key elements were still considered in the studies. They are thought-provoking knowledge, students' own choice of the roles, and peer-led discussions.

In conclusion, literature circle technique has been implemented in many studies with different forms both for online and offline classes. Therefore, the researchers believed that this model can be implemented to organize cooperative learning activities inside the classroom. According to the above reviewed literatures, the researchers decided to adapt the traditional literature circles to organize cooperative learning tasks in speaking lessons for the participants in Class 10A4. In this study, the researchers still implemented the three key components of literature circle (thought-provoking knowledge, students' own choice on the roles, and peer-led discussions) to build up the implementing literature circles in the chosen context and participants of 10A4 Class - Thai Nguyen High School - Thai Nguyen - Vietnam.

\section{III. RESEARCH METHODOLOGY}

\section{Experimental speaking lessons}

The study implemented literature circle technique in 4 experimental speaking lessons using cooperative learning model. The teacher was trained carefully by the researchers to design and carry out the first lesson. For the next three ones, the teacher would create by herself and ask for the observer's comments before teaching them for the participants. The process of running a literature circle in cooperative learning in speaking lessons at the selected class included many sub-steps which are mentioned as follows:

* Getting started with Literature Circle technique

* Planning for Literature Circles used for Cooperative Learning in Speaking Lessons

* Organizing Literature Circles for Cooperative Learning in Speaking Lessons:

- Teacher introduces the Literature Circle technique

- Students choose roles within a group

- Students work with Literature Circle Technique

- Teacher evaluates the group's work

- Students do a final reflection after working towards Literature Circle Technique.

In the next circles, the teacher continued to follow the above steps to organize literature circle activities for the students. But at these times, students were not allowed to choose the roles they wanted but to rotate the roles with their group mates. The circles were continued until all the participants of a group took all four roles.

\section{Participants and Data collection instruments}

The major participants were 47 students of Class 10A4 and 10 English teachers at Thai Nguyen High School. Besides, one practical teacher was invited to teach the four experimental speaking lessons.

In this study, the researchers used three instruments to collect the data for the study, which are questionnaires, observations and interviews. Firstly, many researchers mention that questionnaires provide quick and largely correct responses of the participants (Linda, 2010 \& Othman et al., 2015). However, if the respondents are required to provide their names in the questionnaires, the results are somehow not really reliable. Therefore, the researchers designed anonymous questionnaires, which allow students to answer the questions honestly. Secondly, it is believed that there are several outstanding features of observation as a research tool. Among them, the most distinctive one is that observation provides the researchers "the 'live' data from naturally occurring social situations" (Cohen, et al., 2007). This research instrument is able to explore the participants' specific behaviors and attitudes in real situations that they may not express in questionnaires and interviews. To collect the data to test the outlined hypotheses, the researchers decided to use the highly structured observations the observation checklist. Finally, Cohen, et al. (2007) describe that interview is a useful research tool to gather the data for studies, and it helps the researchers achieve several purposes. However, this study utilized the interview to fulfill the two main purposes which are to test the hypotheses and explore the teacher's attitudes after teaching 4 trial lessons.

\section{IV. FINDINGS AND DISCUSSION}

The current state of students' cooperative learning at grade 10

Q1: When working in cooperative tasks, the group members' amount of work is: 


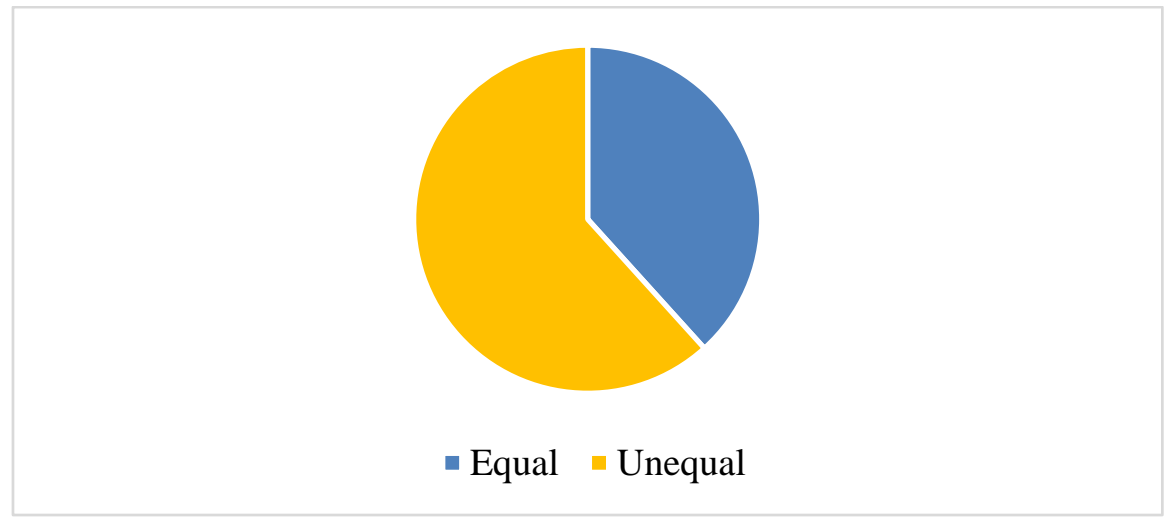

Figure 1: Member's responsibility

The data obtained here revealed that the group members took the unbalanced responsibilities. The position of the students who reported that the members in their groups had unequal amount of work, accounting for $61.7 \%$, and the rest believed that they had equal duties in the group. With the unequal responsibilities within a group, students were not motivated to actively participate in group work (Wang, 2017). Therefore, the learners might not fully get involved in accomplishing the cooperative assignments.

Q2: How do you think about the results of cooperative learning?

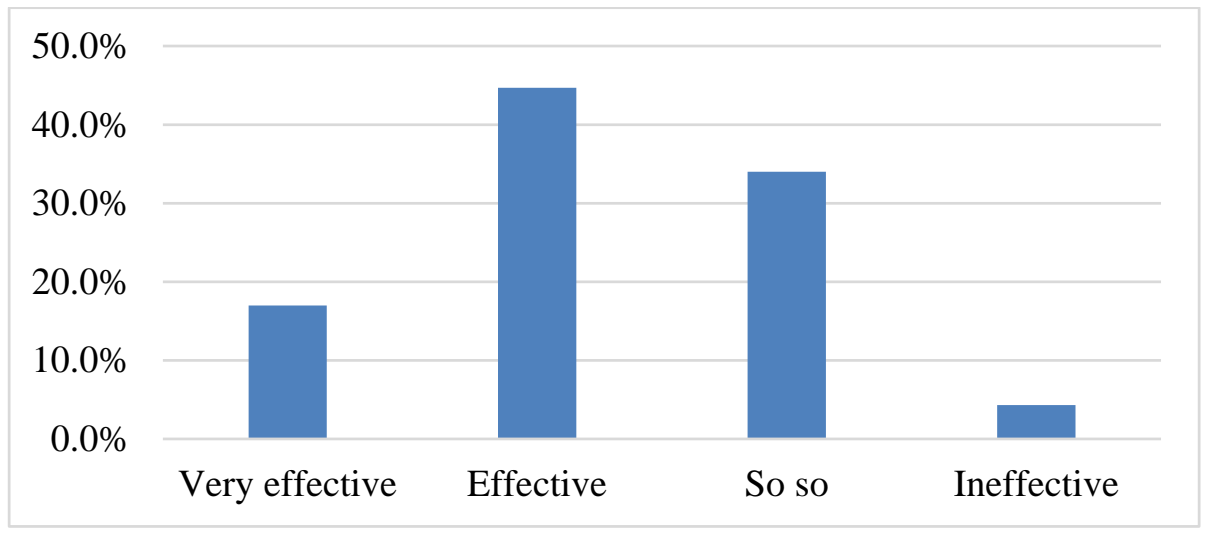

Figure 2: Students' position towards cooperative learning's result

Nearly $45 \%$ of the respondents reported that cooperative learning produced effective results to their studies, and more than $15 \%$ of them even claimed that this method brought to them the very effective results. However, there were still nearly $35 \%$ of the participants admitted that the results were So so and $4.3 \%$ of them thought it was ineffective to their learning. This might be due to the fact that some of the group members just kept silent and did not share their ideas in group discussions and left the cooperative tasks for the high achievers. As a result, the group work was monopolized by the more able students, and the low achievers might feel the cooperative learning tasks were not effective for learning.

Basing on the findings from questionnaires, we could say that cooperative learning at grade 10 was not really effective due to several reasons. Firstly, although the majority of the participants said that the teachers very often assigned cooperative learning in the class (using more than $50 \%$ of a lesson for cooperative learning), some of them did not realize that. Being so, we might say that the cooperative tasks were not clearly defined by the teacher. Secondly, there were still many learners who just listened during the group discussions and left the tasks for the high achievers to accomplish. There was even the monopolization of the more able learners over the group discussions. This might be the consequences of the participants' unbalanced role in group work, which prevented them from building positive interdependence with each other within groups.

\section{Teachers' Difficulties on Organizing Cooperative Learning}

Q3: I do not know how to balance each student's amount of work in one group. The leaders and more able students often do most of the work. 


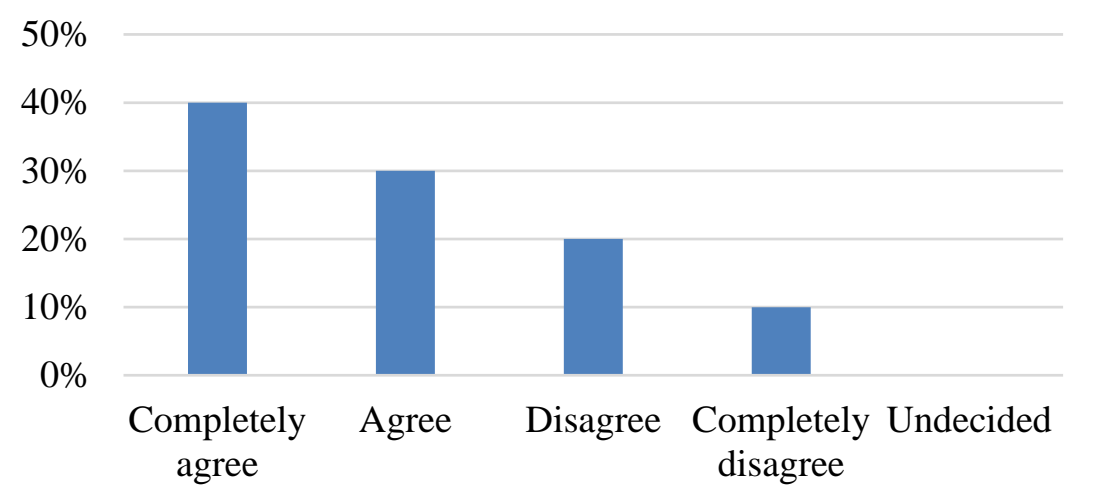

Figure 3: Teachers' difficulty in balancing students' work within groups

The figure showed that a higher proportion of the teachers responded that they had difficulty in balancing the group members' amount of work (40\% of Completely agree and 30\% of Agree) while there were 2 teachers disagreed and 1 completely disagreed with this. This might be due to the unequal training among the teachers. However, in cooperative learning, students are required to take the equal participation in the group by the careful structure (Coachpll, 2015), so it is necessary to find out the strategy to help the teachers be able to balance the students' responsibilities in cooperative groups.

Students' and Teachers' Attitudes upon Using Literature Circle Technique as a Main Method to Organize and Work in Group in Speaking English Lessons

\section{Results from Observations}

$1=$ not at all; $2=$ very little; $3=$ a little; $4=\mathrm{a}$ lot $5=$ a very great deal of

\begin{tabular}{|c|c|c|c|c|c|c|}
\hline Observed Behaviors & Lessons & 1 & 2 & 3 & 4 & 5 \\
\hline \multirow{4}{*}{$\begin{array}{l}\text { Teacher provides the effective instructions of the roles in } \\
\text { literature circle. }\end{array}$} & 1 & & & $\mathrm{X}$ & & \\
\hline & 2 & & & & $\mathrm{X}$ & \\
\hline & 3 & & & & $\mathrm{X}$ & \\
\hline & 4 & & & & & $\mathrm{X}$ \\
\hline \multirow{4}{*}{$\begin{array}{l}\text { Students question, explain, suggest and provide feedbacks in } \\
\text { English orally for each other within the circle }\end{array}$} & 1 & & & $\mathrm{X}$ & & \\
\hline & 2 & & & $\mathrm{X}$ & & \\
\hline & 3 & & & & $\mathrm{X}$ & \\
\hline & 4 & & & & $\mathrm{X}$ & \\
\hline \multirow[t]{4}{*}{ Students fulfill their roles successfully. } & 1 & & $\mathrm{X}$ & & & \\
\hline & 2 & & & $\mathrm{X}$ & & \\
\hline & 3 & & & $\mathrm{X}$ & & \\
\hline & 4 & & & & $\mathrm{X}$ & \\
\hline \multirow{4}{*}{$\begin{array}{l}\text { Teacher performs the role of facilitator and observer } \\
\text { successfully. }\end{array}$} & 1 & & $\mathrm{X}$ & & & \\
\hline & 2 & & & $X$ & & \\
\hline & 3 & & & & $\mathrm{X}$ & \\
\hline & 4 & & & & & $\mathrm{X}$ \\
\hline \multirow[t]{4}{*}{ Teacher takes the monopolization of the class. } & 1 & & & $\mathrm{X}$ & & \\
\hline & 2 & & $\mathrm{X}$ & & & \\
\hline & 3 & & $\mathrm{X}$ & & & \\
\hline & 4 & $X$ & & & & \\
\hline \multirow[t]{4}{*}{ High achievers dominate the group discussions } & 1 & & & $\mathrm{X}$ & & \\
\hline & 2 & & $\mathrm{X}$ & & & \\
\hline & 3 & $\mathrm{X}$ & & & & \\
\hline & 4 & $\mathrm{X}$ & & & & \\
\hline \multirow[t]{4}{*}{ The group discussions are led by the students themselves } & 1 & & $\mathrm{X}$ & & & \\
\hline & 2 & & & $\mathrm{X}$ & & \\
\hline & 3 & & & & $\mathrm{X}$ & \\
\hline & 4 & & & & & $X$ \\
\hline
\end{tabular}




\begin{tabular}{|c|c|c|c|c|c|c|}
\hline \multirow[t]{4}{*}{ Students try to discuss in English } & 1 & & & $\mathrm{X}$ & & \\
\hline & 2 & & & & $\mathrm{X}$ & \\
\hline & 3 & & & & $\mathrm{X}$ & \\
\hline & 4 & & & & $X$ & \\
\hline \multirow{4}{*}{$\begin{array}{l}\text { Students build the closer friendships with each other within } \\
\text { groups }\end{array}$} & 1 & & & & $\mathrm{X}$ & \\
\hline & 2 & & & & $\mathrm{X}$ & \\
\hline & 3 & & & & & $\mathrm{X}$ \\
\hline & 4 & & & & & $\mathrm{X}$ \\
\hline \multirow[t]{4}{*}{ Students speak English freely and confidently } & 1 & $\mathrm{X}$ & & & & \\
\hline & 2 & & $\mathrm{X}$ & & & \\
\hline & 3 & & & $\mathrm{X}$ & & \\
\hline & 4 & & & $\mathrm{X}$ & & \\
\hline \multirow{4}{*}{$\begin{array}{l}\text { Teacher and students try to build the open, and interesting } \\
\text { learning environment }\end{array}$} & 1 & & & & $\mathrm{X}$ & \\
\hline & 2 & & & & $\mathrm{X}$ & \\
\hline & 3 & & & & & $\mathrm{X}$ \\
\hline & 4 & & & & & $\mathrm{X}$ \\
\hline \multirow{7}{*}{$\begin{array}{l}\text { Teacher produces the lesson with full five suggested steps: } \\
\text { Introduce the Literature Circle technique, Choose roles within } \\
\text { a group, Work with Literature Circle Technique, Evaluate the } \\
\text { group's work, Do a final reflection after working towards } \\
\text { Literature Circle Technique }\end{array}$} & 1 & & & & & $\mathrm{X}$ \\
\hline & 2 & & & & & $\mathrm{X}$ \\
\hline & 3 & & & & & $\mathrm{X}$ \\
\hline & 4 & & & & & $\mathrm{X}$ \\
\hline & 2 & & & $\mathrm{X}$ & & \\
\hline & 3 & & & & $\mathrm{X}$ & \\
\hline & 4 & & & $\mathrm{X}$ & & \\
\hline \multirow{4}{*}{$\begin{array}{l}\text { Teacher evaluates the groups' products by both teacher's } \\
\text { observations and students peer-evaluation }\end{array}$} & 1 & & & & $\mathrm{X}$ & \\
\hline & 2 & & & & & $\mathrm{X}$ \\
\hline & 3 & & & & & $\mathrm{X}$ \\
\hline & 4 & & & & & $\mathrm{X}$ \\
\hline
\end{tabular}

Table 1: Observations' Results

The table represented the researchers' observations results of four implemental lessons. As can be clearly seen from the table, there were many differences among the four lessons, basing on the five-point scale of observed behavior. Firstly, the effectiveness of teacher's instructions of the roles in literature circle increased through the four lesson from A little in the first lesson to $A$ great deal of in the forth one. Secondly, students' positive interdependence and simultaneous interaction were also improved when they spent $a$ little time questioning, explaining, suggesting and providing feedbacks in English orally for each other within the circle in the two first lessons to take $a$ lot of time to do so. That is to say, students cooperated within groups more and more effectively. Next, the learners tried to fulfill their roles successfully through the four lessons. In the first trial lesson, the pupils completed their roles very little, this might be because of the students' low English proficiency on average, however, they tried their best to complete the roles $a$ little and $a$ lot in the next sections. Fourthly, the teacher also became more and more familiar with her new role as a facilitator and observer instead of an instructor as before. The result for this behavior varied from very little to a great deal of.

Students' Attitudes upon Using Literature Circle Technique as a Main Method to Organize and Work in Group in Speaking English Lessons

Q4: Do you enjoy talking to the other students in your literature circle group?

\begin{tabular}{|l|l|l|}
\hline Questionnaire items & Frequency & Percent (\%) \\
\hline Yes & 37 & $78.7 \%$ \\
\hline No & 10 & $21.3 \%$ \\
\hline
\end{tabular}

Table 2: Students' interaction within literature circles

The table revealed that nearly $80 \%$ of the respondents said Yes to the question Do you enjoy talking to the other students in your literature circle group? It could be said that literature circles helped the learners to improve the interaction with each other.

Q5: I feel more free and confident to share my ideas about my roles with the group mates in literature circles than in traditional cooperative learning. 


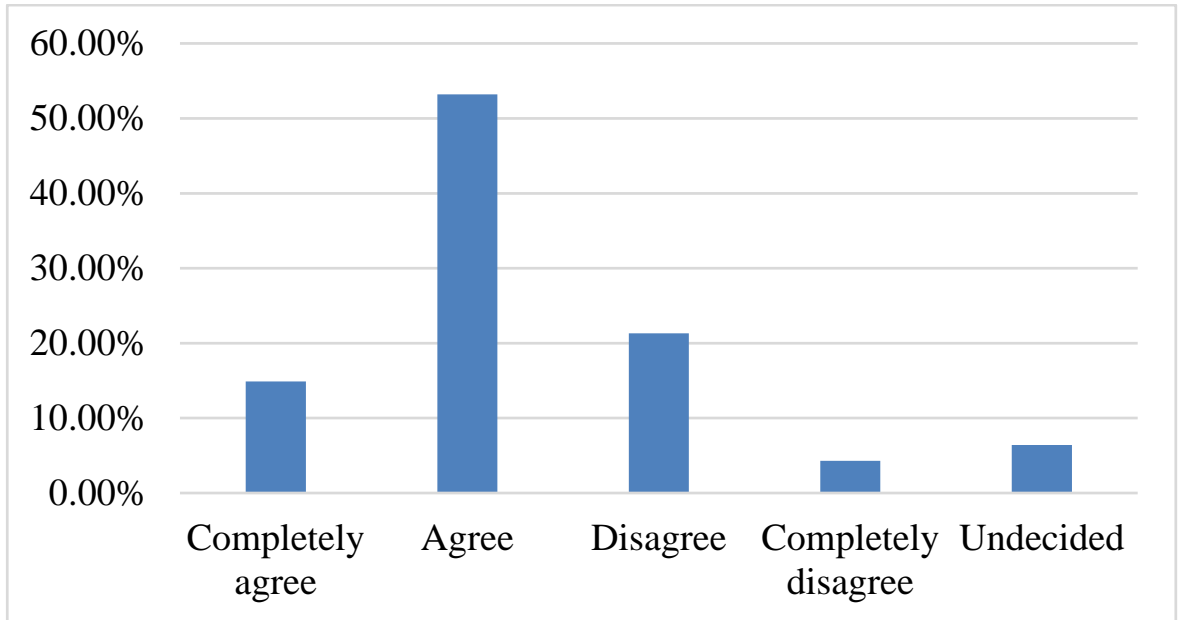

Figure 4: Students' feelings towards literature circles

While there were some learners choosing the options Disagree, Completely disagree, and Undecided, the majority of them said that they could share ideas related to their roles freely and confidently in literature circles (14.9\% of Completely agree and 53.2\% of Agree). That is to say, literature circle technique helped the students to overcome the fear of losing face in speaking English in front of other classmates.

Q6: I am more motivated to work when receiving assessment from both the teacher and my group members.

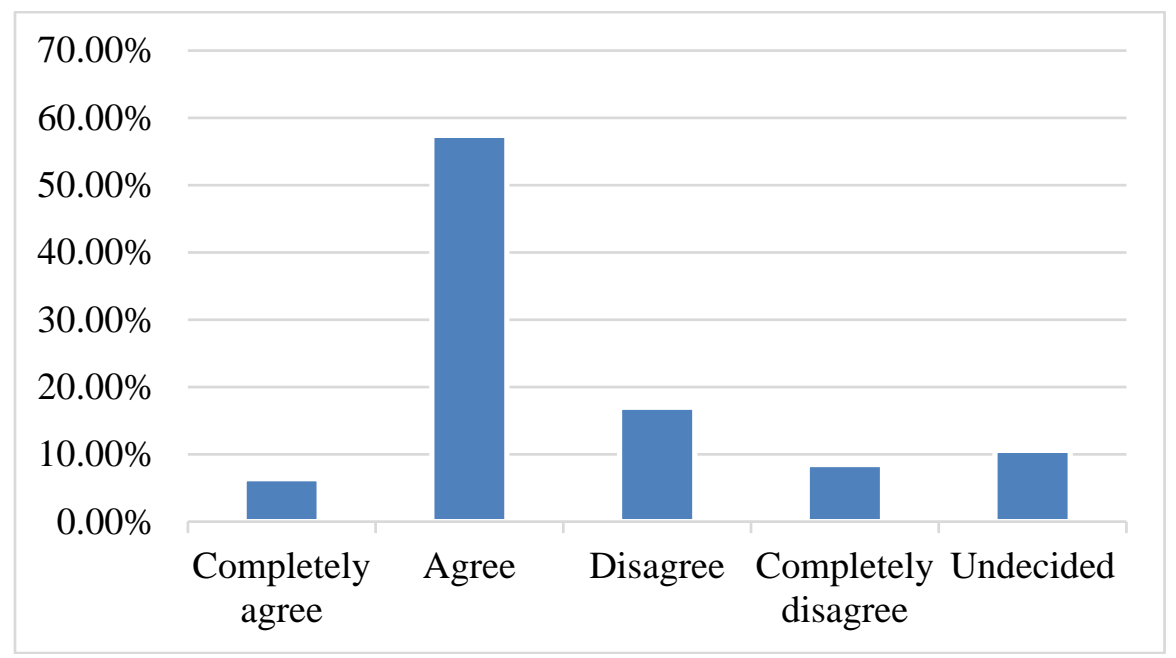

Figure 5: Students' motivation towards assessment method in literature circles

The data obtained here revealed that the number of the students who totally agreed and agreed with the statement that I am more motivated to work when receiving assessment from both the teacher and my group members were as twice and a half as that of Completely disagree and Disagree respondents. Therefore, it could be concluded that literature circle technique offered the effective evaluation method which helped to improve students' learning motivation. By using both teacher's observation and group mates' evaluation, literature circles gave the students chances to assess the other members' performances and receive the peer-assessment from the others.

\section{CONCLUSION}

In short, although literature circle technique is proved as a helpful approach to organize cooperative learning in speaking lessons, there are still some implications on both teachers and students. Therefore, the researchers would like to bring in some pedagogical suggestions for the implementations. Firstly, due to the fact that literature circle technique is still a new teaching approach in Vietnam, if the teachers want to implement literature circles as a long-term teaching approach, they must study carefully about the technique by reading the studies about literature circle model or taking training courses of using it. Besides, it is advisable for the teachers to practice carefully prior to going to the class. Furthermore, there are a variety of studies pointing out that assigning students roles make peer-led discussions reduce its liveliness, and the students are give less freedom in their discussions. Thus, the teachers should allow the students to decide which roles will work in the class and which roles they want to take in the discussions. Others suggestions for implementing literature circles in cooperative learning are that the students should take full advantage of literature role sheets in order to remain the 
group discussions, and that teachers are advised to motivate individual participations by foster students to use self-assessment forms. Besides, according to the reviewed literatures in this study, the researchers can conclude that literature circle technique has been implemented for several different groups of students, with different forms (online and offline), in different contexts. Therefore, this teaching approach can be used across grade levels as well as language skills lessons.

\section{REFERENCES}

[1] Bedee, S. (2010). The Impact of Literature Circles on Reading Motivation and Comprehension for Students in a Second Grade Classroom.

[2] Carrison, C. (2005). From Silence to a Whisper to Active Participation: Using Literature Circles with ELL Students. 94-113.

[3] Coachpll. (2015). Group Work VS Cooperative Learning? Retrieved from \#OklaEd Instructional Coach Blog: https://pcinstructionalcoach.wordpress.com/2015/04/28/group-work-vs-cooperative-learning/

[4] Coccia, L. (2015). Literature Circles and Their Improvement of Comprehension.

[5] Cohen, C., Manio, L., \& Morrison, K. (2007). Research Methods in Education (6th ed.). London and New York: Routledge.

[6] Daniels, H. (2002). Literature circles: Voice and choice in book clubs and reading groups.

[7] Daniels, H. (2006). What's the next big thing with literature circles? Voices from the Middle, 13, 10-15.

[8] Dillon, J. (2007). Widening the Circle: Adapting Literature Circles for the College Level Developmental Reading Class. Research and Teaching in Developmental Education, 83-86.

[9] Jacobs, G. M., Power, M. A., \& Inn, L. W. (2002). The Teacher's Sourcebook for Cooperative Learning. Thousand Oaks: Sage Publication.

[10] Jacobs, M. (2015). Using literature circles to increase reading comprehension and student motivation.

[11] Kagan, S. \& Olsen, R. E. (1992). About Cooperative Learning. In C. Kessler, Cooperative Language Learning: A Teacher's Resource Book (pp. 1-30). Englewood Cliffs, N.J.: Prentice Hall Regents.

[12] Lin, M. (2009). Effects of Cooperative Learning on the Oral Proficiency of Chinese Students in the Tertiary-level EFL Classroom.

[13] Linda, H. (2010). Cooperative Learning and Learners' Opportunities to Participate in English Foreign Language Class the Case of Second Year Pupils at Soumani Mehmoud Secondary School-Kherrata.

[14] Long, T. W., \& Gove, M. K. (2003). How engagement strategies and literature circles promote critical response in a fourth-grade urban classroom. The Reading Teacher, 57, 350-361.

[15] Othman, H., \& Murad, I. (2015). A Study on Kurdish Students Attitudes to Group Work in the EFL Classroom. European Scientific Journal, $290-303$.

[16] Petty, G. (2001). Teaching Today, A Practical Guide.

[17] Thomas, A. (2014). An Action Research Study Involving Motivating Middle School Students' Learning through Online Literature Circles. Journal of Ethnographic \& Qualitative Research., 44-54.

[18] Wang, E. (2017). Improving Students' Oral Skills Through A Cooperative Approach to Teaching Chinese College English.

[19] Williams, R. B. (2002). Cooperative Learning: a Standard for High Achievement. Corwin Press. Retrieved from https://books.google.com.vn/books?hl=vi\&lr=\&id=YiVI6tEF34sC\&oi=fnd\&pg=PP1\&dq=cooperative+learning:+a+standard+for+high+achievement++williams+2002\&ots=lt-GtBin40\&sig=ZZ_Fz0PtFur-jD3RysZxWamt-wU\&redir_esc=y\#v=onepage \&q\&f=true

[20] Zhang, H. (2010). A comparative study of the use of language learning stratgies by oral English high achievers and low achievers in vocational college cooperative learning (Unpublished master's thesis).

\section{AUTHORS}

First Author - Pham Thi Kieu Oanh, Foreign languages education faculty, Thai Nguyen University of Education

Second Author - Dinh Thi Lien, Foreign languages education faculty, Thai Nguyen University of Education 